\title{
Redes aristocráticas mexicanas a principios del siglo XX en Álbum de Damas. Revista quincenal ilustrada (1907)
}

\author{
Alma Liliana Vargas Aguirre *
}

Recibido el 27 de enero de 2020; aceptado el 10 de mayo de 2020

\section{RESUMEN}

El porfiriato fue un período en el que se vivió un gran crecimiento económico en México. Socialmente, esta prosperidad se vio reflejada, entre otras cosas, en las grandes fiestas y eventos realizados por y para las familias de las clases altas privilegiadas. Por otra parte, hubo un auge en la producción de medios impresos, particularmente proliferaron las revistas dirigidas a las damas del hogar y de la aristocracia mexicana. Una de ellas fue Álbum de Damas, publicación que se mantuvo entre enero de 1907 y julio de 1908, en la que se incluía una sección donde se describían los principales eventos sociales de las clases altas. El objetivo de este artículo es analizar las redes aristocráticas reflejadas en dicha sección, Ecos sociales de la quincena, de la revista Álbum de Damas, en los 24 números publicados en 1907. Analizar la revista en general es revelador en cuanto a su intención, similar a la de otras revistas de la época dedicadas a las mujeres, de educar o instruir a la mujer mexicana de acuerdo con un modelo que cumpliera con los roles convenientes para la nación y para el desarrollo de los futuros ciudadanos que servirían a la patria. Pero centrar el análisis en la sección social de la revista nos presenta toda una nueva perspectiva, pues a través del análisis de redes se pu-

* Universidad de Colima, Colima, México. Correo electrónico: alvaxli.07@gmail.com. ORCID: https://orcid.org/0000-0003-1038-344X. 
dieron visibilizar conexiones muy reveladoras en cuanto a vida social, política, estatus, influencias de poder y economía. Entender estas conexiones nos da un enfoque alternativo para comprender las dinámicas económicas y políticas de esa clase encargada, tal vez de manera indirecta, de dirigir el rumbo del país.

Palabras clave: México, porfiriato, siglo $\mathrm{xx}$, redes, aristocracia, revistas femeninas.

\section{Mexican aristocratic networks in the early twentieth century in Álbum de Damas. Revista quincenal ilustrada (1907)}

\section{Abstract}

The porfiriato was a period of great economic growth in Mexico. Socially this prosperity was reflected, among other things, in the great parties and events held by and for the families belonging to the most privileged upper classes. On the other hand, during this period there was also a boom in the production of print media, particularly magazines aimed at housewives members of the Mexican aristocracy. One of these magazines was Álbum de Damas, published between January 1907 and July 1908, which included a section describing the main social events of the upper classes. The objective of this article is to analyze the aristocratic networks reflected in the section Ecos sociales de la quincena, of the above mentioned magazine. This analysis was performed in the 24 issues published in 1907. A general analysis of this magazine is revealing as to its intention, which was similar to that of other contemporary magazines dedicated to women: to educate Mexican women according to a model that would fulfill the appropriate roles for the nation and for the development of the future citizens who would serve their homeland. Focusing the analysis on the social section of the magazine presents us with a whole new perspective, because through the analysis of networks, very revealing connections in terms of social life, politics, status, influences of power, and economy made themselves visible. Comprehending these connections provides us with an alternative approach to understand the economic and political dynamics of these classes, responsible (perhaps indirectly) of setting the country's agenda.

Key words: Mexico, porfiriato, 20th century, networks, aristocracy, women's magazines. 


\section{INTRODUCCIÓN}

L

a época del porfiriato (1876-1911) ha sido analizada desde diferentes

$\checkmark$ perspectivas, desde la que sólo juzga una dictadura hasta la que idealiza un paraíso perdido, pero uno de los enfoques que ha predominado ha sido el económico, y es innegable que México tuvo un gran crecimiento económico durante ese período. Dentro de ese auge fueron pocas las familias que se repartieron las riquezas del país, una clase social que tenía un estilo de vida muy particular, en el que las reuniones sociales, los grandes bailes, los encuentros en clubes deportivos y culturales, fueron muy importantes para la conservación de su estatus. ${ }^{1}$

En este período también hubo un auge en la producción de la prensa, gran parte de ella dirigida a las clases altas, y cuyas publicaciones son registros tangibles del estilo de vida de las familias aristocráticas. De manera particular proliferaron aquellas dedicadas al público femenino. Durante la segunda mitad del siglo XIX hubo un auge de revistas, semanarios o secciones especiales en medios periodísticos, dedicados a las mujeres, ${ }^{2}$ entre ellos: La Mujer (1880-1883), La Familia (1883-1892), El Correo de las Señoras (1883-1893), El Álbum de la Mujer (1884-1888), Las Hijas del Anáhuac (1887-1888), Violetas del Anáhuac (1888), El Mundo (1894-1899), El Periódico de las Señoras (1896), El Mundo Ilustrado (1900-1914) y La Mujer Mexicana (1904-1906).

Iniciando ya el siglo XX surge Álbum de Damas. Revista quincenal ilustrada (1907-1908), que desde el primer número se declara como una revista dirigida a las damas del hogar, con consejos relacionados al cuidado de la belleza, de la casa, de los hijos, con poesías, cuentos y relatos, con información sobre la moda proveniente de Europa, y con una sección en particular, Ecos sociales de la quincena, en la cual se describen todos los detalles de los principales eventos sociales en los que coinciden las familias de la aristocracia mexicana, incluyendo en varias ocasiones a la familia del mismo presidente y de su esposa.

En la búsqueda de investigaciones previas acerca de Álbum de Damas, se encontró mencionada como ejemplo de las revistas que había en la época porfiriana, ${ }^{3}$ o como ejemplo de las primeras revistas dedicadas a la mujer en

1 Ugalde, Arte y letras o la construcción del imaginario social de la élite porfiriana, 19041912, pp. 202.

2 Torres y Atilano, "La educación de la mujer mexicana en la prensa femenina durante el Porfiriato”, pp. 217-242. Torres y Atilano vinculan este auge con el objetivo de los gobiernos del México independiente para impulsar la educación de sus lectoras.

3 Ortiz, Imágenes del deseo: arte y publicidad en la prensa ilustrada mexicana, 1894-1939, pp. 440; Frías, "La prensa en tiempos de don Porfirio", 
México. ${ }^{4}$ Tales textos presentan enfoques centrados en diferentes campos, como el de la historia de la publicidad, de la prensa o su análisis ideológico, la historia de la educación o el análisis del género en la historia de las publicaciones impresas. El propósito del presente artículo está enfocado en presentar resultados de un enfoque desde el análisis de redes, orientado a la historia de las élites a través del análisis de las redes aristocráticas reflejadas en la revista Álbum de Damas.

El primer artículo que describe un poco más su contenido fue el de Gustavo Romero en 2014, titulado Lectura y prácticas ideales. Álbum de Damas. ${ }^{5}$ Es un artículo descriptivo, donde menciona de manera muy breve algunas de las secciones de la revista y la inclinación conservadora de sus contenidos, apegados a los ideales porfiristas. Después se enfoca en una descripción más profunda de la sección La cocina y la mesa, en la que Romero imprime también sus opiniones sobre la internacionalización de las recetas presentadas.

Pero quien más ha indagado en las raíces de Álbum de Damas ha sido la historiadora Paola Ugalde. En 2013 publicó el libro Arte y letras o la construcción del imaginario social de la élite porfiriana, 1904-1912, ${ }^{6}$ en el que hace un análisis alrededor de la revista Arte y Letras, explorando en la vida del director, Ernesto Chavero, y en el proceso de la editorial Arte y Letras, de la que también nació Álbum de Damas en 1907; después, Ugalde se centra en analizar el contenido de la revista Arte y Letras, sus secciones, años de circulación, las características que la definieron, así como el discurso de la revista relacionado con la vida cotidiana de la mujer.

Del mismo trabajo de investigación se desprende un artículo titulado Ernesto Chavero: de funcionario público a empresario editorial, 1874-1921, publicado en 2016 en la Revista de Historia de América; ${ }^{7}$ en este artículo, Ugalde se centra más en la vida de Chavero, en sus raíces, sus contactos con

https://algarabia.com/a-curiosidades/la-prensa-en-tiempos-de-don-porfirio, [consultado el 9 de octubre de 2018].

4 Derreza, "Guía de revistas femeninas olvidadas",

https://www.letraslibres.com/mexico-espana/guia-revistas-femeninas-olvidadas, [consultado en octubre de 2018]; Terán, "Instruir a los ángeles del hogar. La educación de las mujeres desde la perspectiva de dos periódicos locales: El Instructor y El Republicano, en la etapa porfiriana”, pp. 77-84.

5 Romero, “Lectura y prácticas ideales. Álbum de Damas”, https://www.correodelmaestro.com/publico/html5102014/capitulo2/album_de_damas.html, [consultado en octubre de 2018].

6 Ugalde, Arte y letras o la construcción del imaginario social de la élite porfiriana, 19041912, pp. 202.

7 Ugalde, “Instantánea de un porfiriano. Ernesto Chavero: de funcionario público a empresario editorial, 1874-1921”, pp. 165-88. 
la política, en cómo su formación y actitud emprendedora lo llevaron al mundo editorial, creando no sólo una revista, sino una editorial. Aunque el interés de Ugalde no se centra en Álbum de Damas, sino en Arte y Letras, su investigación sirve mucho para comprender el proceso por el que nació la revista, y su segunda publicación al respecto, enfocada en Chavero, ayuda para adentrarnos un poco más en las redes que pudo haber detrás de la publicación.

Algo interesante de la época en la que surgió Álbum de Damas es que la prensa ya no era del todo libre, para los últimos años de la dictadura porfirista tenía básicamente dos opciones: "doblegarse a la fuerza de la subvención estatal o resignarse a la persecución constante". ${ }^{8} \mathrm{Al}$ analizar el discurso de Álbum de Damas es de suponer que pertenecía al grupo de la primera opción, pues el contenido de la redacción coincide con el discurso oficial de progreso, del seguimiento de las modas extranjeras; la primera sección de cada número, titulada Ecos sociales de la quincena, está enfocada a dar nota de los eventos sociales y del estilo de vida de la aristocracia.

Es por estas características que la hipótesis que se plantea es que en la sección Ecos sociales de la quincena de la revista Álbum de Damas podemos encontrar redes que reflejan la vida social de la aristocracia mexicana de principios del siglo XX, las cuales visibilizan las conexiones entre el estatus social, la política, las influencias de poder y la economía del país.

Un primer objetivo en este artículo es conocer las redes aristocráticas reflejadas en la sección Ecos sociales de la quincena de la revista Álbum de Damas en sus números del 1 al 24, mismos que pertenecen a los meses de enero a diciembre de 1907. Después, como segundo objetivo, se podrán analizar las conexiones entre la vida social de la élite aristocrática y los grupos políticos y de poder que manejaban la economía del país.

Para cumplir con los objetivos se utilizó el análisis de redes como metodología desde las ciencias sociales, que consiste en el estudio de las conexiones o enlaces dentro de una estructura social, interesándose por las relaciones entre diferentes entidades sociales: individuos, organizaciones, grupos, etcétera. ${ }^{9}$ Aunque en el campo de la historia, en un primer momento, se ha enfrentado al problema de la capacidad demostrativa, por el encuentro entre la cuantificación de los datos con la narración histórica y el análisis crítico de las fuentes, el análisis de redes ha demostrado ser un método útil e innovador en diversos trabajos historiográficos, como los relacionados con la historia colonial o la intelectual; ${ }^{10}$ en el nivel macro histórico, esta meto-

Serna, "Prensa y sociedad en las décadas revolucionarias (1910-1940)", p. 122.

Garrido, "El análisis de redes en el desarrollo local”, pp. 67-89.

Iglesias, "El aporte del análisis de las redes sociales a la historia intelectual”, pp. 17-37. 
dología ha reactivado el uso de la prosopografía o la biografía colectiva como método de la historia tradicional, mientras que en el nivel micro histórico "ha facilitado el estudio de las relaciones personales de un individuo (familiares, de amistad, laborales, e incluso de clase), fundamentalmente de aquéllos que pertenecieron en algún período determinado a una élite económica, política, social o cultural”. ${ }^{11}$ Es precisamente el interés por las relaciones de los individuos que la metodología de redes fue la más conveniente para esta investigación, pues se busca conocer y analizar las conexiones entre los miembros de la élite porfirista.

En el siguiente apartado se realizará un recorrido por la historia del surgimiento de la revista, dirigida por el licenciado Ernesto Chavero, así como una descripción de la misma, incluyendo sus características físicas y el contenido de sus secciones. En la segunda parte se realiza un análisis de las redes que representa la revista y que corresponden a las clases altas de la sociedad porfirista del siglo Xx. Se hablará del proceso metodológico que se llevó al utilizar el análisis de redes y se hará una comparación entre los resultados encontrados y los estudios relacionados a las clases sociales de la época. Por último, se presentan las reflexiones finales de este análisis.

\section{UNA PUBLICACIÓN PARA EL “BELLO SEXO”. ERNESTO CHAVERO Y EL NACIMIENTO DE LA REVISTA}

Hablar de Álbum de Damas implica hablar de Ernesto Chavero, el fundador y director de la revista, quien fue un emprendedor de su época, pues además de introducirse en la vida política desde muy joven, también incursionó en distintos proyectos industriales, culminando con la creación de una casa editora. Su éxito puede deberse a diversos factores, entre ellos el haber nacido en una familia que ya estaba integrada a la política y haber pertenecido a la élite porfirista, pero además porque "tuvo la habilidad de hacerse de redes sociales, políticas y económicas que le permitieron formar su empresa”. ${ }^{12}$

Educado en un ambiente intelectual de escritores, historiadores y políticos, Ernesto Manuel Luis Chavero Rosas siguió los pasos de su padre al estudiar Derecho e integrarse en la política mexicana el mismo año que finalizó sus estudios, en 1896, iniciando como diputado suplente del Tercer Distrito del Distrito Federal. Aunque algunos de sus detractores opinaran que su ingreso en la política era debido a la influencia de su progenitor, Chavero continuó con ese camino, consiguiendo ser diputado local en la

11 Pita, “Las revistas culturales como fuente para el estudio de redes intelectuales”, pp. 77-85.

12 Ugalde, “Instantánea de un porfiriano”, p. 166. 
Legislatura XVII un año después, en 1897; en 1900 fue nombrado miembro del Congreso de la Unión, donde ejerció como diputado federal propietario por el 3er. Distrito del Estado de México, cargo en el que permaneció 12 años. ${ }^{13}$

Mientras se desempeñaba en la vida política, también realizó varios proyectos emprendedores, aprovechando el programa Nuevas Industrias impulsado por las políticas de promoción empresarial del gobierno del país. Particularmente en 1989 —año en el que además contrajo matrimonio con Beatriz Hijar y Haro Millán- presentó diversas propuestas de empresas, algunas de ellas con su socio Gregorio E. González. Entre los proyectos que intentó desarrollar estuvieron: una fábrica fundidora de fierro, fábrica de alambre, de máquinas de coser, de leche condensada, de máquinas de escribir, entre otros. ${ }^{14}$

En el campo editorial incursionó en 1904, lanzando al mercado la revista Arte y Letras. Aventurarse en este tipo de empresa requería una gran inversión, considerando la maquinaria, las nuevas técnicas de impresión de la época y el costo de mantenerse en circulación. Por ello buscó el patrocinio del presidente Porfirio Díaz, suponiendo que estaría interesado en subvencionar una publicación que informaba sobre las novedades de la sociedad política y de la élite capitalina. Aunque no se han encontrado documentos que comprueben el apoyo económico del gobierno a su empresa editorial, se sabe que había subvenciones no oficiales, por ejemplo, la de El Imparcial, publicación subsidiada mediante una partida de la Secretaría de Gobernación que no requería justificación, por lo que se podría pensar que eso mismo pudo haber sucedido con Arte y Letras. ${ }^{15}$

Esta primera publicación logró cumplir ocho años en el mercado, de manera ininterrumpida, además de que abrió las puertas al mundo editorial para Ernesto Chavero. En este contexto se inserta Álbum de Damas. Revista quincenal ilustrada, una revista dirigida a las mujeres de la élite mexicana, que lanza su primer número el 1 de enero de 1907. El siguiente año, los Talleres de Arte y Letras se convierten en la "Compañía editorial Arte y Letras, S.A.”, fundada por Chavero junto a José I. Bandera, Alfredo Hijar y Haro y Roberto N. Portilla. En esta compañía se editó, además de Arte y Letras y Álbum de Damas, el libro El Señor Root en México, que consistía en una crónica de la visita a México del Secretario de Estado y titular del Departamento de Defensa de Norteamérica. ${ }^{16}$

\footnotetext{
Ugalde, “Instantánea de un porfiriano”, p. 167.

Ibíd., p. 170.

Ibíd., p. 172.

Ugalde, “Instantánea de un porfiriano”, p. 173.
} 
Álbum de Damas se produjo durante 1907 y 1908; el primer año se imprimía quincenalmente, mientras que el segundo año comenzó a reproducirse cada semana, aunque a partir de entonces la cantidad de páginas disminuyó casi a la mitad que el año anterior. Finalmente, en su edición número 54, la revista anuncia que se unirá a Arte y Letras para formar entre ambas una "Revista de Hogar", ${ }^{17}$ concluyendo así el 30 de julio de 1908 con la publicación de Álbum de Damas.

\section{CARACTERÍSTICAS DE ÁlbUM DE DAMAS}

Desde el primer número mantuvo un estilo de contenido estable, con características relacionadas con una idea de progreso y refinamiento dentro de los hogares mexicanos, en los que la mujer cumpliría un papel clave. Como lo dejó claro en sus primeras páginas, el objetivo de la revista era entretener e instruir a las damas mexicanas:

Al sugerirnos la idea de hacer la presente revista, tuvimos en cuenta como primer factor, el progreso alcanzado por el hogar en México (...) Las damas que carecen de lectura a propósito, que esté en relación con su sexo, que las instruya de ese conjunto de conocimientos finos y necesarios, indispensables para su vida (...) Unir lo ameno a lo útil, hacer que la dama encuentre algo que la deleite y mucho que la sirva, es nuestro ideal. ${ }^{18}$

En esa misma edición, después de la bienvenida que da La Redacción, se publicó una fotografía de Carmen Romero Rubio de Díaz, la primera dama y esposa de Porfirio Díaz. La imagen estaba editada con un ramo de flores detrás de la fotografía, con su nombre y un pequeño texto en donde se le elogia. La intención, además de alabar a la primera dama "por quien simboliza lo dulce, lo delicado, esas joyas riquísimas de alma femenina”, ${ }^{19}$ probablemente fue la de posicionar la revista entre las damas de las familias de clase social alta, mediante argumentos que resaltan las dotes femeninas a emular en la élite para ser parte de lo más distinguido de la sociedad en su tiempo, objetivo que se reafirma en la sección Ecos sociales de la quincena, donde se describían los detalles lujosos de las grandes fiestas celebradas en

17 Comp. Editorial Arte y Letras, S.A., “A nuestras suscritoras”, Álbum de Damas. Semanario ilustrado, Ciudad de México, 30 de julio de 1908.

18 La Redacción, “A nuestras lectoras”, Álbum de Damas. Revista quincenal ilustrada, Ciudad de México, 1 de enero de 1907.

19 Ibíd. 


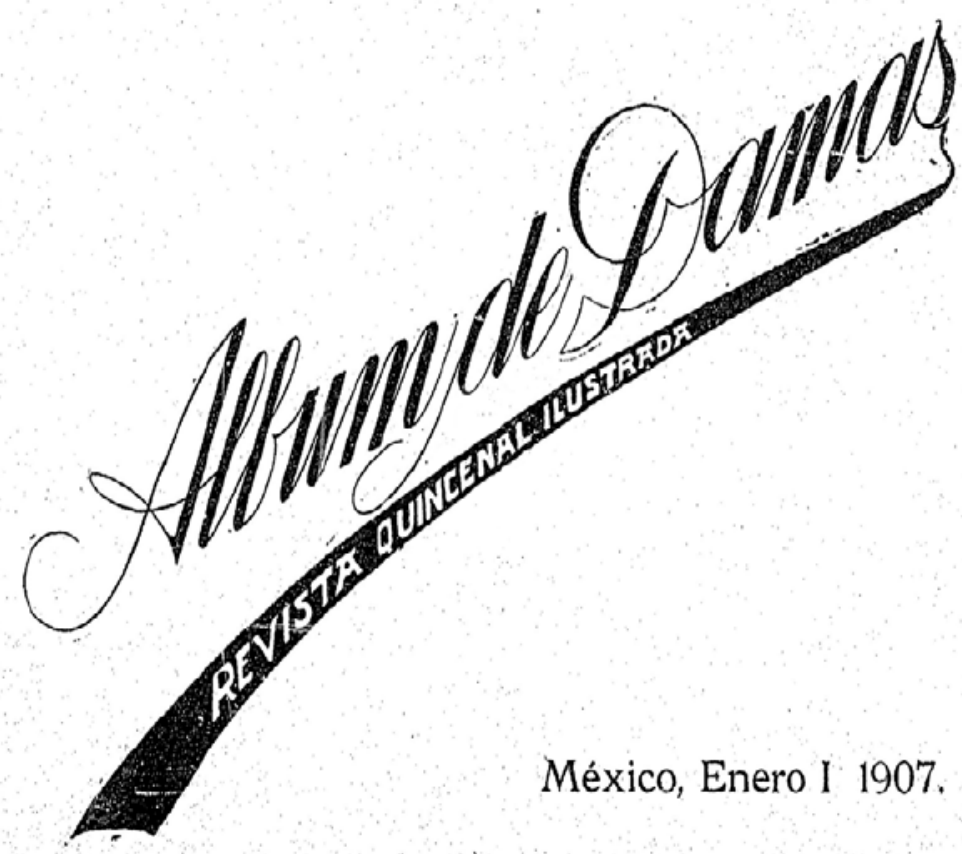

Imagen 1. Portada.

Fuente: Álbum de Damas, enero de 1907. Hemeroteca Nacional Digital de México.

la capital, mencionando los apellidos de las familias anfitrionas y de los principales invitados.

El precio de suscripción era de 1.25 al mes en la capital, y de 1.50 en los estados, pero se pedía realizar el pago bimestralmente. Su valor hace alusión al tipo de público al que se dirigía la publicación, que era un precio similar al de otras revistas de ese mismo estilo, actuando de alguna manera como diferenciación social de las clases alta y media; esta diferencia se remarca al compararlo con los 25 centavos que costaba El Álbum de la Mujer (1883- 
1901 $)^{20}$ o incluso con los 50 centavos que llegó a costar La Mujer Mexicana (1904-1906), ${ }^{21}$ ambas revistas dirigidas a las mujeres de la élite.

Durante los primeros meses de publicación, la revista tenía un tamaño tipo cuaderno y contenía alrededor de 40 páginas. La portada de su primera edición era simple, un fondo claro con el título de la revista en una tipografía cursiva (Imagen 1). En la primera página se presentaba una versión mucho más ornamentada del nombre de la revista, que incluía flores, el dibujo del rostro de una mujer y líneas curvas que enmarcaban la página (Imagen 2).

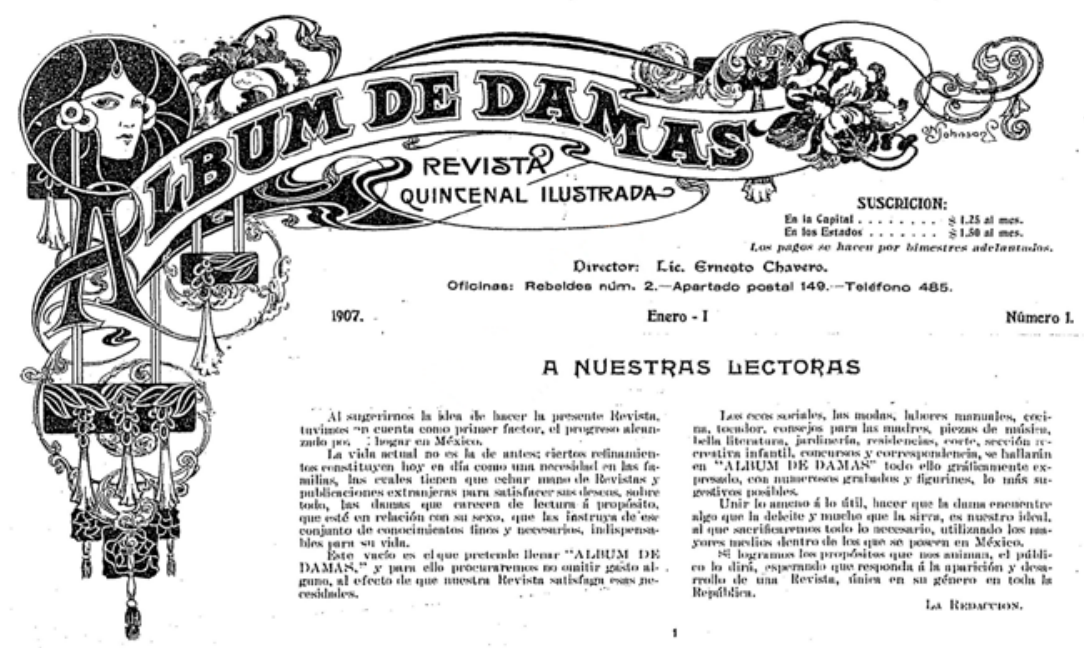

Imagen 2. Primera página.

Fuente: Álbum de Damas, enero de 1907. Hemeroteca Nacional Digital de México.

Tales características de ornamentación correspondían a las propias del movimiento cultural conocido como Art Nouveau, nacido en París entre finales del siglo XIX y principios del $\mathrm{XX} .^{22}$ Entre sus elementos visuales destacan los trazos curvilíneos y asimétricos, como los que aparecen en la

20 Derreza, “Guía de revistas femeninas olvidadas”, https://www.letraslibres.com/mexico-espana/guia-revistas-femeninas-olvidadas, [consultado en octubre de 2018]

21 Martín, “La Mujer Mexicana (1904 a 1906), una revista de época”, pp. 68-87.

22 Fontbona, "Las raíces simbolistas del Art Nouveau”, pp. 213-222. 
primera página de Álbum de Damas, en la que el título de la revista parece estar sobre una banda que se ondea; la primera letra está también representada con líneas que asemejan listones o látigos que se atraviesan formando la A. Ese coup-de-fouet, o latigazo en francés, era precisamente una de las expresiones que popularmente ya se relacionaban con el aspecto del Art Nouveau ${ }^{23}$ Otra imagen característica de esta corriente era la inspirada por figuras femeninas místicas o provenientes de la fábula, similar al rostro de mujer que formaba parte de la decoración de la revista, el cual se muestra a medio perfil rodeado por sus propios cabellos oscuros y largos, con la mirada seria dirigida hacia los lectores.

El Art Nouveau influyó también en la joyería, ${ }^{24}$ que compartía las características de la representada en esta primera página, con broches, anillos, colgantes y pendientes, como el que se dibuja en la frente de la mujer, parecido a una piedra en forma de gota, o los aros colocados a la altura de las orejas. La naturaleza fue otro elemento de este estilo decorativo, como las guías de flores y hojas ubicadas entre la mujer y la banda que se ondea, que pasan por detrás, hacia arriba y hacia abajo, hasta terminar en el extremo derecho con unas flores. De las flores se desprenden un par de líneas que forman el nombre del autor de la ornamentación: Johnson. Por debajo de la A cuelgan también esas guías, formando tres adornos, que son como flores que miran hacia abajo. En el interior de la revista también solía haber ornamentación en algunos de los artículos, aunque más sencilla que la presentada en la imagen 2, generalmente eran guías de flores o grecas enmarcando el título o como marco de página.

La presencia de elementos del Art Nouveau en la revista es un ejemplo de la influencia de las modas europeas en el México porfirista, que se ve reflejado no sólo en el diseño gráfico sino también en el contenido de las secciones, entre las que se incluían una amplia gama de temas considerados femeninos, desde recetas de cocina, instrucciones de corte y confección, jardinería, consejos para las madres relacionados con la crianza de los hijos, moda, consejos de belleza, entre otros; así mismo, se incluían secciones sobre arquitectura, poemas, partituras musicales, reseñas de las fiestas de la alta sociedad; con relación a la interacción con las lectoras, la revista hacía sorteos mensuales para las damas y para los niños del hogar, además de tener una sección donde respondía cartas enviadas por las consumidoras de la publicación.

Para la vestimenta estaba la sección Modas, que era a la que se le dedicaban más páginas y más imágenes, en ella se exhibían los vestidos más 
elegantes de Europa y se escribía acerca de los accesorios adecuados, como guantes, abanicos, sombreros, tipos de encaje, flores o plumas. El gusto por lo extranjero era una característica no solamente de las damas, sino de la sociedad mexicana en general. Por ello, en la sección La cocina y la mesa se observa una tendencia a utilizar y apropiarse de ingredientes, formas y modos extranjeros; encontrándose una clara diferenciación entre la pequeña y la "gran cocina”, ${ }^{25}$ en la que casi todos los platillos incluidos tenían un estilo a la francesa, a la alemana, a la inglesa, etcétera. Así mismo, en diferentes secciones se encuentra el uso de extranjerismos como: office, hall, chalet, sport, entre otros.

Es probable que el éxito de la revista haya sido mayor del que esperaba su director, por lo que, en tan sólo cuatro meses, el 1 de mayo de 1907, Álbum de Damas ya anunciaba su primer cambio con modificaciones que fueron principalmente de imagen, dimensión y el agregado de algunas secciones. El tamaño aumentó al doble, “y su forma antes apaisada se ha sustituido por la forma usual de las revistas extranjeras del mismo género". ${ }^{26}$ También se anunciaron más contenidos ilustrados con fotograbados, secciones que incluían artículos literarios, cuentos, novelas, poesías, comedias de salón, crónicas teatrales y las fotografías de las principales artistas del teatro.

Ciertamente hubo cambios desde las primeras páginas, en las que se incluyó un sumario que no existía en ediciones anteriores. El precio continuó igual, a pesar de contener mayor número de fotografías y grabados. Entre otras modificaciones físicas de la revista, se observó un encabezado más sobrio en la primera página, con una tipografía sin ornamentación. La redacción, que antes era a una o dos columnas, ahora era a cuatro, el número de página se hizo más pequeño y se ubicó en la esquina superior externa de la hoja, cuando antes se situaba en la parte inferior central.

Estos cambios, principalmente el relacionado con el aumento de tamaño de la edición y mayores contenidos, probablemente haya sido consecuencia de la mayor inclusión de publicidad dentro de la revista. En los primeros números no había anuncios; en la octava edición sí se observaron algunos, pero solamente en las últimas páginas. Y a partir de la novena edición nos encontramos con un anuncio de página completa ya desde la contraportada, publicidad de ropa para mujeres de la tienda Al puerto de Veracruz. A

25 Romero, “Lectura y prácticas ideales. Álbum de Damas”, https://www.correodelmaestro.com/publico/html5102014/capitulo2/album_de_damas.html, [consultado en octubre de 2018].

26 “Grandes mejoras en esta revista”, Álbum de Damas. Revista quincenal ilustrada, Ciudad de México, 1 de mayo de 1907. 
partir de esa edición, cada número de la revista incluía un anuncio de dicho almacén en su contraportada.

La publicidad, además de evidenciar el tipo de público al que se dirige, es también un reflejo de la época, del contexto social y temporal en que se inserta la revista. La publicidad nos habla no solamente del objeto que se oferta, sino de la "imagen del objeto", ${ }^{27}$ de los beneficios que aporta al consumidor, tales como salud, prestigio, pertenencia a una clase o posesión, es decir, le aporta un boleto de ingreso a un estilo de vida determinado.

En Álbum de Damas, los anuncios encontrados son principalmente de almacenes de novedades como Al puerto de Veracruz, El centro mercantil, The dry goods store in Mexico, El palacio de Hierro o El paje, que ofrecían objetos como sombreros, flores para adornar las prendas femeninas o que anunciaban el crecimiento de sus departamentos de confecciones; productos para la apariencia como Sedería y Corsetería Francesa, sombreros de Señoritas Aguilar, crema rosada Adelina Patti, para conservar el cutis; productos higiénicos Benzo Boranina; productos de salud para las señoras y sus familias como Píldoras nacionales, Ozomulsión, o Fosfo alimento Banck dirigido a niños y personas débiles; o anuncios de doctores como el doctor Ricardo Suárez Gamboa, que se promovía como especialista en enfermedades de señoras, o el doctor Pedro P. Peredo, ofreciendo sus servicios de especialista en enfermedades de señoras y niños; también se repetía un anuncio del colegio superior Sara L. Keen, Escuela Americana para señoritas, niñas y párvulos, y la propaganda de palmistas o tarotistas, como la señora A.G. Miller, doctora Annie Douglas o Mme. Rachel.

Como puede observarse, la mayoría de la publicidad va dedicada a las mujeres, el público para el que está pensado la revista, y el tipo de objetos ofertados por la revista nos hablan de la importancia de conservar buena salud y sobre todo buena apariencia, desde la figura modificada por el corsé hasta las prendas de moda extranjera que se deben vestir para acceder a ese mundo de sueños anhelado. ${ }^{28}$ Estas características, encontradas en la publicidad, en el contenido de las secciones, en el estilo místico del Art Nouveau y en las fotografías de figuras femeninas admiradas, como la de la primera dama, reforzaban la construcción idealizada de la dama aristocrática al que se aspiraba llegar. 


\section{LOS ECOS SOCIALES DE LA ARISTOCRACIA CLASES SOCIALES DURANTE EL PORFIRIATO}

El tema de las diferenciaciones de clases se vuelve complejo al analizar el período del porfiriato, o al menos si lo comparamos con el presente. Según Tenorio y Gómez, ${ }^{29}$ la vida obrera porfiriana tenía formas culturales que chocan con todas nuestras distinciones de clase, se podía ser indio y poderoso, o se podía estar en el poder, pero no ser aceptado por la aristocracia.

Esto no niega el problema de raza, al contrario, durante el porfiriato la desigualdad fue sustentada por un discurso científico de teorías raciales. De acuerdo con Molina Enríquez, las castas son definidas como estratos o capas, cada una de ellas formada por grupos sociales, y sus subgrupos, con elementos particulares relacionados con su origen; se refiere, por ejemplo, a las tribus indígenas, que aunque físicamente estaban desligadas y separadas por el extenso territorio del que provenían, formaban un solo grupo unido por las características que se consideraban parte de la raza, como "sus condiciones de formación, de carácter y de desarrollo evolutivo". ${ }^{30}$ De esta manera, cada estrato social era una casta, divididas en: extranjeros, criollos, mestizos e indígenas.

Molina Enríquez fue un abogado e historiador mexicano que vivió durante todo el período del porfiriato y conoció de primera mano muchas de sus características. En su libro Los grandes problemas nacionales, ${ }^{31}$ además de ser crítico con la política en curso, hace una descripción de las características y sucesos que fueron ocurriendo en el país y que, para él, no habían permitido el desarrollo adecuado de México, desde un extenso recuento de las tribus indígenas precoloniales hasta el análisis de las leyes de reforma sobre la propiedad, y cómo éstas últimas afectaban a las diferentes castas. A partir de las castas, Molina Enríquez hace una distinción entre clases altas, medias y bajas, de acuerdo a si son privilegiadas, medias o trabajadoras (Imagen 3).

Al analizar Álbum de Damas, específicamente la sección Ecos sociales de la quincena, es posible distinguir a las castas que formaban las clases altas de México, así como las relaciones entre ellas. Para esto fue necesario aplicar una metodología de análisis de redes, cuyo proceso se presenta a continuación junto con las gráficas resultantes de los datos extraídos de la sección Ecos sociales de la quincena, de la revista Álbum de Damas, tomándose en cuenta la clasificación expuesta por Molina Enríquez, así como información acerca de los apellidos aristocráticos de la época.

29 Tenorio y Gómez, El Porfiriato, pp. 166.

30 Molina Enríquez, Los grandes problemas nacionales, p. 340.

31 Ibíd., pp. 552. 


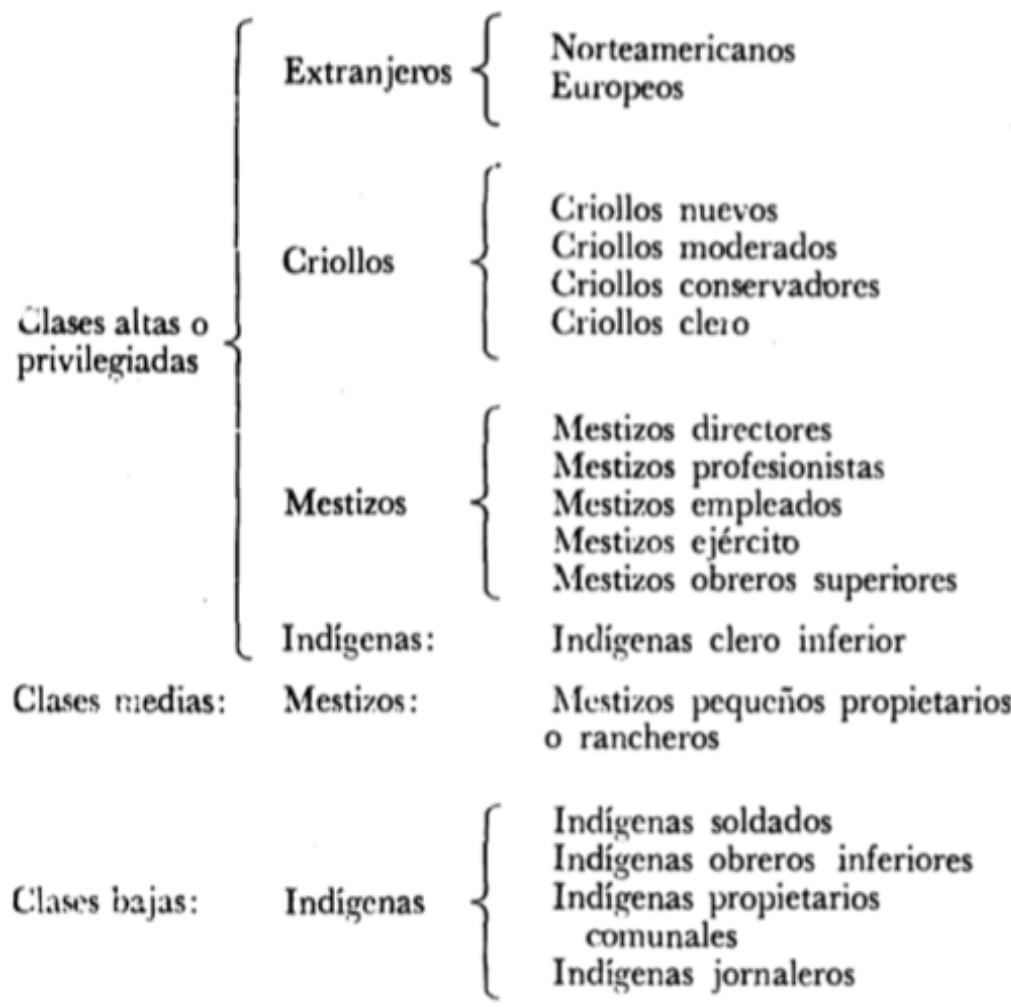

Imagen 3. Clases en el porfiriato. Molina Enríquez (1985).

\section{ANÁLISIS DE REDES}

En el proceso de análisis se utilizó FileMaker para la captura de datos de los números del 1 al 24 de Álbum de Damas. FileMaker es un programa que permite sistematizar la información de manera práctica y personalizada, con este software se pueden crear bases de datos integrando la cantidad y el tipo de campos que sean necesarios. Para el interés de esta investigación, se recopiló la información de cada uno de los eventos mencionados en la sección Ecos sociales; se registraron los nombres de todos los asistentes a cada evento, diferenciándolos entre anfitrión (que podía ser quien organizaba el evento o la persona homenajeada) e invitados (el resto de la concurrencia). Se obtuvieron 118 menciones de eventos y 1052 menciones de asistentes, entre invitados y anfitriones. Una vez que se capturaron y sistematizaron todos los datos, se pasó al programa Gephi para proceder a la creación de las gráficas. 
Gephi es un software de fácil acceso que permite visualizar la información en forma de redes, por lo que se pueden analizar grandes cantidades de datos de manera práctica.

A grandes rasgos, las redes están creadas por nodos, que pueden representar a personas, grupos, organizaciones, lugares, eventos, etcétera, y por vínculos o enlaces entre éstos. Las características de las relaciones entre nodos y de la estructura de la red en general es lo que constituye el objeto de análisis de las redes, aunque pueden distinguirse aproximaciones distintas para su estudio desde las ciencias sociales, como la sociocéntrica, que explica las propiedades de un grupo de nodos previamente definidos y sus conexiones, y la egocéntrica, que analiza las conexiones que se pueden delinear a partir de un ego dado. ${ }^{32}$ La centralidad es uno de los principios fundamentales del análisis de redes sociales por su capacidad para describir y examinar las propiedades de la estructura de la red, puede ser entendida como centralidad global, en función de las características de la red en general, o centralidad nodal, que analiza la relación que mantiene un nodo con el resto de ellos. ${ }^{33}$

Para los fines de este artículo nos inclinamos a la aproximación egocéntrica de los análisis de redes sociales y nos enfocamos en los conceptos de centralidad a nivel nodal. Uno de ellos es el de grado, que indica la actividad de relaciones de un nodo con sus nodos contiguos directos, es decir que, a mayor número de nodos vinculados directamente, mayor grado. ${ }^{34}$ En el caso de este análisis, por ejemplo, los nodos de anfitriones tendrán mayor grado entre mayor número de invitados hayan asistido a su evento.

Otro concepto es el de cercanía, que se refiere a la distancia más corta de un nodo con respecto a otro, ya sea de manera directa o a través de la mediación de otros nodos; este elemento tiene que ver con la capacidad de alcanzar el mayor número de relaciones con el menor número de pasos. ${ }^{35}$ En nuestro análisis, el interés de analizar este recurso radica, entre otras cosas, en conocer el nivel de cercanía entre los personajes relacionados directamente con la vida política del país y el resto de las familias de la élite aristocrática.

El tercer elemento de la centralidad nodal es el de intermediación, que sirve para identificar la capacidad que tiene un nodo para conectar pares de

32 Molina, “El estudio de las redes personales: contribuciones, métodos y perspectivas”, pp. 71-105

33 Lozares, López-Roldán, Bolíbar, Muntanyola, “La centralidad en las redes sociales: medición, correlación y aplicación”, pp. 77-97.

34 Ibíd., p. 81.

35 Lozares et al., “La centralidad en las redes sociales”, p. 81. 
nodos en la red, es "la suma de la combinación de todos los pares de nodos de la red que para comunicarse entre sí por el camino más corto (el de menos pasos) han de pasar necesariamente por el nodo en cuestión”. ${ }^{36}$ La importancia de la intermediación radica en el potencial como puente de información y comunicación entre dos nodos que no se comunican, y por eso mismo es un agente que ayuda en la consistencia de la red, haciéndola menos vulnerable a la anulación y desaparición de algunos de sus nodos. ${ }^{37}$

Retomando la clasificación de castas de Molina Enríquez, dentro de las clases altas y privilegiadas coexistían los extranjeros -grupo en el que se incluía a los norteamericanos y los europeos-, los criollos, la mayor parte de los mestizos y el grupo indígena que formaba parte del clero (Imagen 3). Esta división estaba basada en su carácter de castas privilegiadas o trabajadoras; Molina Enríquez consideró que además de los extranjeros y los criollos, los mestizos (con excepción de los mestizos rancheros) eran parte de la clase privilegiada debido a que vivían de las clases trabajadoras que estaban más abajo, siendo el mismo caso el de los indígenas clero. ${ }^{38}$

Los extranjeros eran la élite más privilegiada, notándose el esfuerzo mexicano en hacerle grata su estancia, pues se pretendía afianzar el poder económico, político y social mediante vínculos sólidos, como en el caso de matrimonios, sociedades mercantiles o compadrazgos políticos. En el primer nivel estaban los norteamericanos, por encima de los europeos, debido en gran medida a que se trataba de un vecino fuerte y poderoso, con el que México había querido evitar roces y dificultades. ${ }^{39}$

Estos esfuerzos descritos por Molina Enríquez se ven reflejados en los principales eventos referidos en Álbum de Damas. Algunas familias aristocráticas lograron emparentar con extranjeros gracias al matrimonio de algunos de sus miembros, como el caso de la unión entre Silvia García Granados, hija del diplomático Ricardo García Granados, con Paul Stockder, originario del entonces reino prusiano; en la descripción de la boda no se menciona al resto de los invitados, probablemente porque Ricardo García ya se había autoexiliado después de haber escrito en los periódicos de oposición El Demócrata y La República, ${ }^{40}$ por lo tanto, la boda de su hija, aunque aún era parte de la clase alta, tal vez no merecía más renglones en la redacción.

Un ejemplo del gran esfuerzo por complacer al extranjero son las fiestas en honor a la visita de Elihu Root, Secretario de Estado y titular del Depar-

\footnotetext{
Ibíd.

Ibíd., p. 85.

Molina Enríquez, “Las clases sociales mexicanas durante el Porfiriato”, p. 67.

Ibíd., p. 61.

Luna, "Verdad y verosimilitud en la historia: retórica, literatura e historia”, pp. 3773-3807.
} 
tamento de Defensa de Norteamérica, realizada en octubre de 1907. Dicha visita tuvo como objetivo fortalecer las relaciones de amistad entre su país y el gobierno mexicano, y para ello se realizaron diversos eventos, ${ }^{41}$ los que se describen en Ecos sociales acompañados de amplios halagos al señor Root y, como era de esperarse, nombrando a la gran cantidad de invitados para legitimar la calidad del festejo. Incluso, en la Gráfica 1 se puede observar que el nodo correspondiente a Elihu Root es el más grande, el que tiene mayor grado de salida, es decir, que los eventos en su honor tuvieron el mayor número de asistentes de todos los eventos registrados (Gráfica 1).

La centralidad de grado a nivel nodal puede interpretarse como signo de influencia, prestigio o prominencia, con mayor visibilidad social por tener una elevada cantidad de relaciones directas, ${ }^{42}$ en el caso del nodo de Elihu

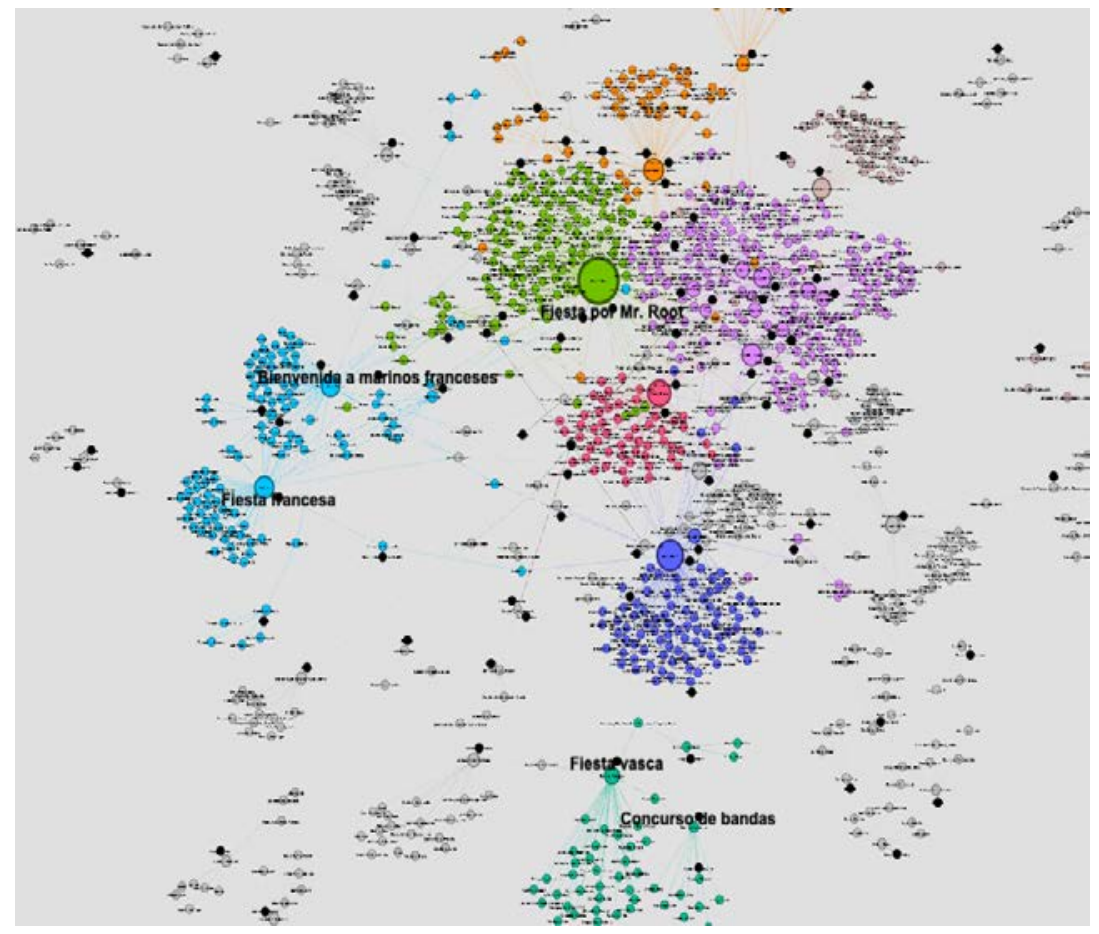

Gráfica 1. Eventos de colonias extranjeras. Elaboración propia.

41 Ugalde, “Instantánea de un porfiriano”, p. 173.

42 Lozares et al., "La centralidad en las redes sociales”, p. 84. 
Root, y considerando lo expresado por Molina Enríquez respecto al interés mexicano en afianzar alianzas con la clase más alta, la de extranjeros norteamericanos, estamos hablando de un personaje con demasiada influencia ya que, además de su país de origen, ostentaba un cargo de prestigio en la vida política y era el representante directo de las relaciones con el país vecino del norte.

En la gráfica, los puntos negros corresponden a los eventos y el resto de los nodos son las personas, ya sean anfitriones o invitados. Respecto a festejos en honor a extranjeros europeos, se describen, entre otros, una bienvenida a marinos franceses, un concurso de bandas organizado por la colonia española, una fiesta francesa y una fiesta vasca. Lo reflejado en Ecos sociales de la quincena coincide con las características expresadas por Molina Enríquez respecto a este grupo: las unidades extranjeras que llegaban al país, antes de mezclarse y transformarse en criollos nuevos, lograban conservar su unión y colocación como un conjunto diferenciado de los otros. ${ }^{43}$

A través de los datos encontrados, se infiere que existía una relación entre la vida social con la vida política y económica, pues, entre otras características, se puede observar la confluencia de las principales familias pertenecientes a la élite política asistiendo a los mismos eventos sociales, los que aparentemente no estaban relacionados con asuntos políticos; coincidían en bodas, bautizos, carreras de caballos, etcétera.

Un caso particular es el de la familia Braniff. Proveniente de Estados Unidos, con ascendencia irlandesa, Thomas Braniff era un joven ambicioso y emprendedor, unido a Lorenza Ricard, de origen francés; ambos llegaron a México en 1865, donde nacieron sus hijos Jorge, Oscar, Tomás, Arturo, Lorenza, Alberto y Rafael. El señor Braniff llegó al país contratado por la empresa Smith Knight para trabajar en la construcción del ferrocarril. Pero más adelante, aprovechando su estatus de extranjero, realizó inversiones que lo llevaron a ser ya reconocido en 1900 como un banquero prominente. Invirtió en mineras, fundidoras, en fábricas de papel y de telas, entre otras cosas. Thomas Braniff falleció en 1905, pero su descendencia continuó generando riquezas consolidando el poder económico familiar, ya fuera uniéndose en matrimonios con la aristocracia mexicana, convirtiéndose en comerciantes, industriales, entrando en la vida política o aventurándose en materia agraria. ${ }^{44}$

43 Molina Enríquez, "Las clases sociales mexicanas durante el Porfiriato”, p. 61.

44 Collado, La burguesía mexicana. El emporio Braniff y su participación política 1865-1920, pp. 174. 


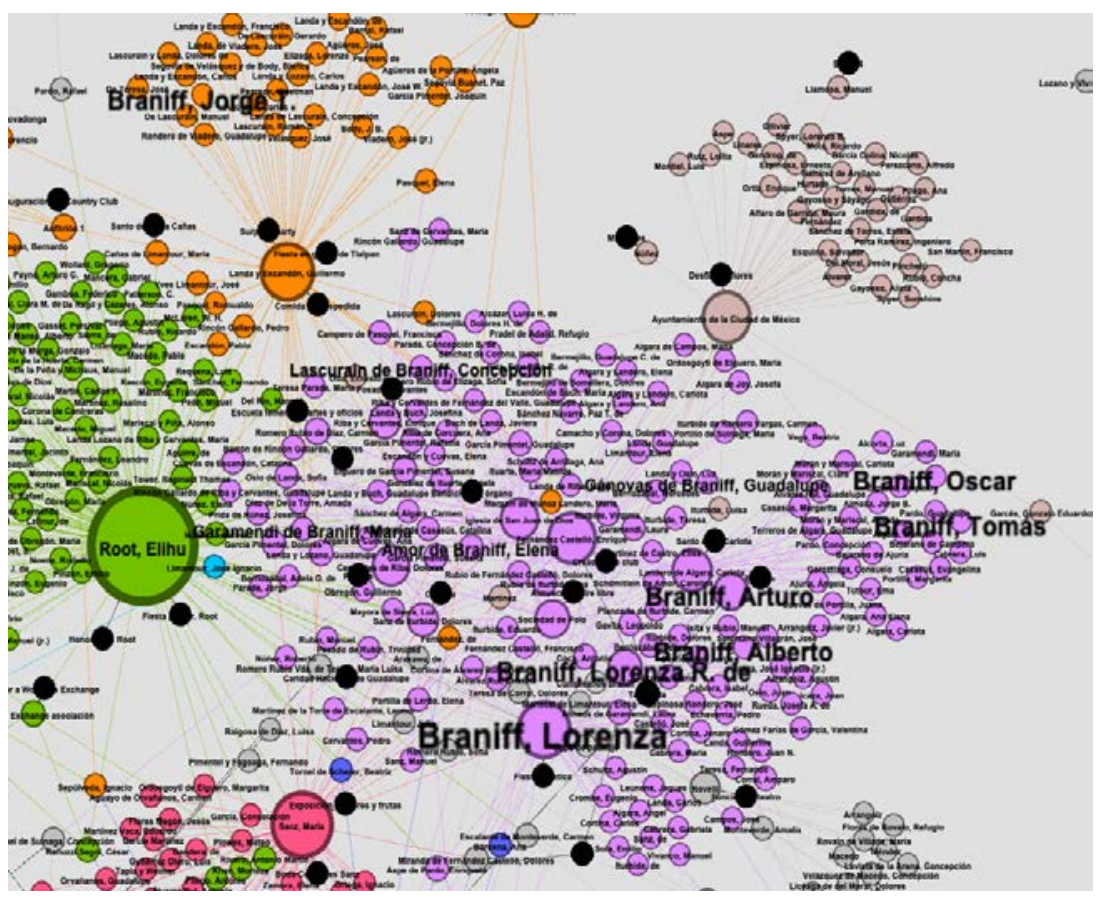

Gráfica 2. Red de la familia Braniff. Elaboración propia.

En el análisis de redes de Álbum de Damas, la más notoria es Lorenza Braniff (Gráfica 2). Tal vez el nodo de Lorenza o de los otros Braniff no son tan sobresalientes como, por ejemplo, el de Elihu Root, sin embargo, en conjunto la familia Braniff fue anfitriona de diferentes eventos, entre ellos una Copa de patinaje, Fiesta artística en la mansión Braniff, el cumpleaños de doña Lorenza Ricard de Braniff, una tamalada organizada por Arturo y Alberto Braniff junto con Enrique Fernández Castelló, y el bautizo del hijo de Arturo Braniff; si uniéramos todos los eventos en los que se relacionan los Braniff en un solo nodo, probablemente sobresaldría más que el resto de los nodos. Es decir, como grupo, el apellido Braniff también representa un nivel de grado sobresaliente, lo que se traduce en un nivel elevado de influencia social entre las familias aristocráticas.

Por otra parte, los eventos en los que se mencionan como invitados, son reuniones tanto familiares como sociales organizadas por instituciones: almuerzo al aire libre organizado por la Sociedad de polo, el santo de Luz González Cosío de López (cuñada del presidente Porfirio Díaz), la bendición 


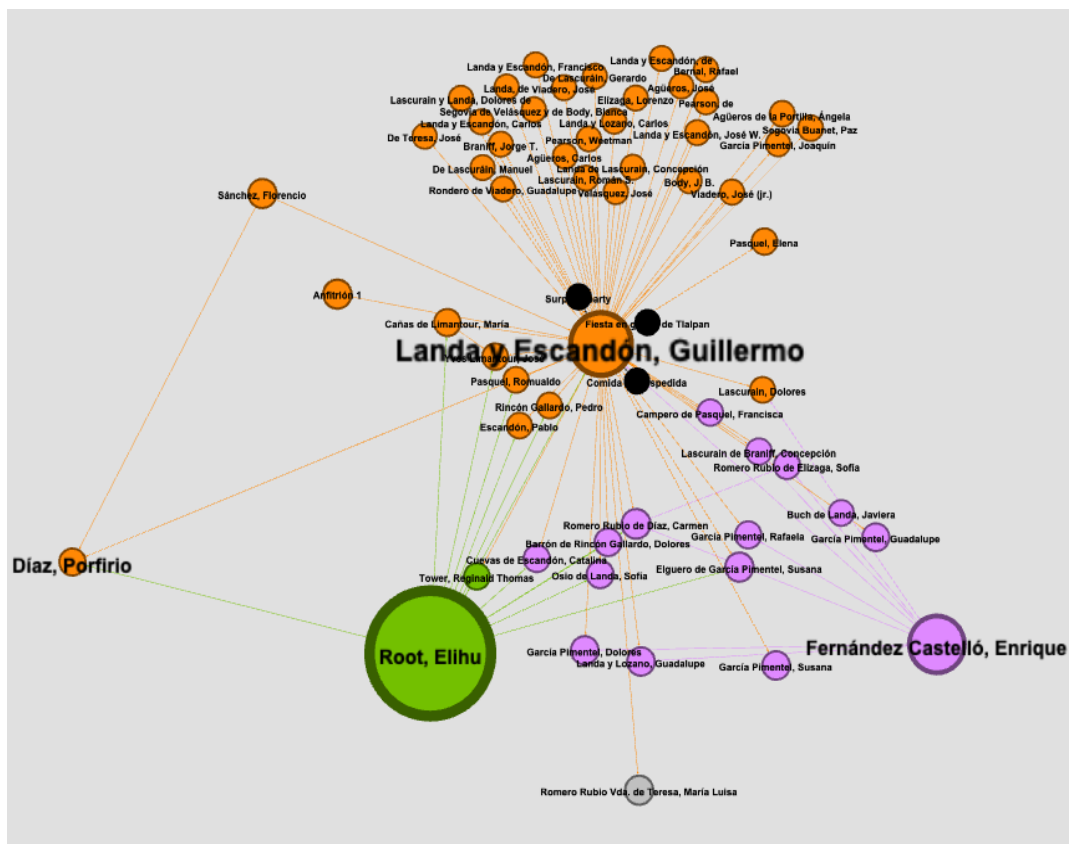

Gráfica 3. Red egocéntrica de Guillermo Landa y Escandón. Elaboración propia.

del órgano de la iglesia San Juan de Dios, el Desfile de flores organizado por el Ayuntamiento de la Ciudad de México, entre otros. Como podemos ver, la familia Braniff estaba muy presente no sólo en la vida social, sino también en la vida política de México, como lo menciona Collado ${ }^{45}$ y como lo refleja este breve vistazo a los Ecos Sociales de 1907 en Álbum de Damas, por lo que, gracias a su posición de prestigio, su nivel de influencia pudo llegar también al ámbito de las decisiones políticas.

Otro nodo, y apellido, sobresaliente es el de Landa y Escandón. Entre 1903 y 1911 Guillermo Landa y Escandón fue el gobernador de la Ciudad de México. A través de sus ocho hijos emparentó con familias económicamente importantes, como los Mier, Limantour, Cañas, Beistegui e Iturbe. ${ }^{46} \mathrm{Al}$ pp. 174.

46 Fierro, “La casa de don Guillermo de Landa y Escandón”, https://grandescasasdemexico.blogspot.com/2012/11/la-casa-de-don-guillermo-de-landay.html, [consultado en marzo de 2019]. 
filtrar la red egocéntrica de Guillermo Landa y Escandón, con un nivel 1 de profundidad ${ }^{47}$ (Gráfica 3), lo vemos directamente relacionado con Porfirio Díaz, con los eventos en honor a Elihu Root, con José Yves Limantour (ministro de Hacienda), con Enrique Fernández Castelló, entre otros. Al subir al nivel 2 de profundidad ${ }^{48}$ en su red egocéntrica (Gráfica 4), encontramos relación con el Ayuntamiento de la Ciudad de México, con la familia Braniff, y con Peretti de la Roca, principal organizador de los eventos de la legación francesa.

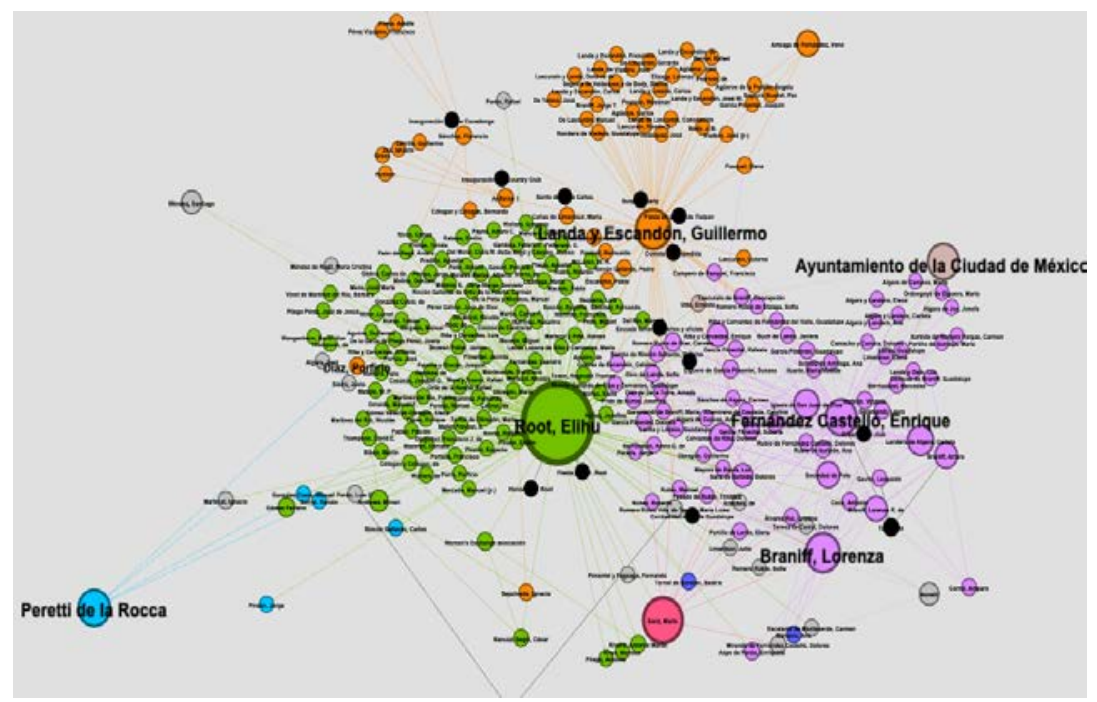

Gráfica 4. Red egocéntrica de Guillermo Landa y Escandón, nivel 2.

Elaboración propia.

Se puede observar que el nodo de Landa y Escandón, además de tener un nivel de grado nodal elevado (es decir, renombre e influencia), también tiene mucha cercanía con la vida política, con la élite extranjera, y con las familias pertenecientes a la aristocracia en general. La interpretación de la cercanía

47 A través del programa Gephi es posible filtrar los nodos que se relacionan con un nodo particular. Al hablar de nivel 1 de profundidad nos referimos a que el programa nos permite ver solamente aquellos que tienen una conexión directa, sin intermediarios, con el nodo en cuestión.

48 En el nivel 2 de profundidad podemos ver los nodos que se relacionan directamente con el nodo que nos interesa y también aquellos que se conectan a través de un intermediario. 
nodal se vincula con la posibilidad de informar e informarse, de apoyar y comunicarse con otros nodos, se considera un recurso valioso de capital social porque se tiene el poder de acceder a gran cantidad de nodos con el menor gasto de recursos. ${ }^{49}$ En el caso de Landa y Escandón, tenía conexión directa con las clases más altas y privilegiadas de la élite porfirista.

Dos apellidos más entre los nodos con mayor centralidad de grado, es decir, con mayor influencia y prestigio por el tipo de conexiones con otros nodos, son el de María Sanz y el de Dante Cusi (Gráfica 5). Respecto a los Sanz Calderón, nacieron siendo parte de la aristocracia mexicana, ambos padres fallecieron pronto, por lo que se criaron entre la opulencia de sus abuelos, los Sanz-Jové, quienes habían logrado su fortuna en haciendas pulqueras en Tlaxcala. Fueron cinco hermanos: Clemente, Dolores, Patricio, María y Manuel; y todos ellos heredaron las fincas de Tlaxcala y numerosas pulquerías en la capital del país. ${ }^{50}$

El nodo de María Sanz es el más grande de los Sanz Calderón, pues en uno de los números de la revista se describe su boda con sus invitados y, en otro, se le presenta como organizadora de una exposición de flores y frutas. Su nodo está conectado directamente con el de su hermana Dolores Sanz de Iturbide, que también es anfitriona de una comida en la mansión de los Sanz, está conectada con la familia Braniff, con los García Pimentel a través de la posada de Dolores Cervantes de Riba, con Luis Fernández Castelló, quien a su vez es invitado de Dante Cusi, entre otros.

Por su parte, Dante Cusi fue un italiano que llegó a México en busca de fortuna a principios del siglo xx. En 1903 compró en Michoacán la hacienda La Zanja, un lugar en el que parecía no crecer nada; él la nombró Lombardía y la convirtió en una de las más productivas y modernas de su época. Lo mismo hizo con otro conjunto de haciendas que, después de comprarlas, las nombró La Nueva Italia, aunque eso fue ya en 1909. Cusi sobresale, entre otras cosas, por su visión modernista en cuestión agraria: realizó los primeros experimentos genéticos en plantas como el limón para adaptarlas al clima de Michoacán, introdujo la primera máquina de vapor para producir aceite de limón y logró producir arroz a gran escala. ${ }^{51}$

49 Lozares et al., "La centralidad en las redes sociales”, p. 85.

50 Saucedo, "La victoria de María Conesa”,

https://relatosehistorias.mx/nuestras-historias/la-victoria-de-maria-conesa, [consultado en marzo de 2019].

51 Pureco, Empresarios lombardos en Michoacán. La familia Cusi entre el porfiriato y la posrevolución (1884-1938), p. 432. 


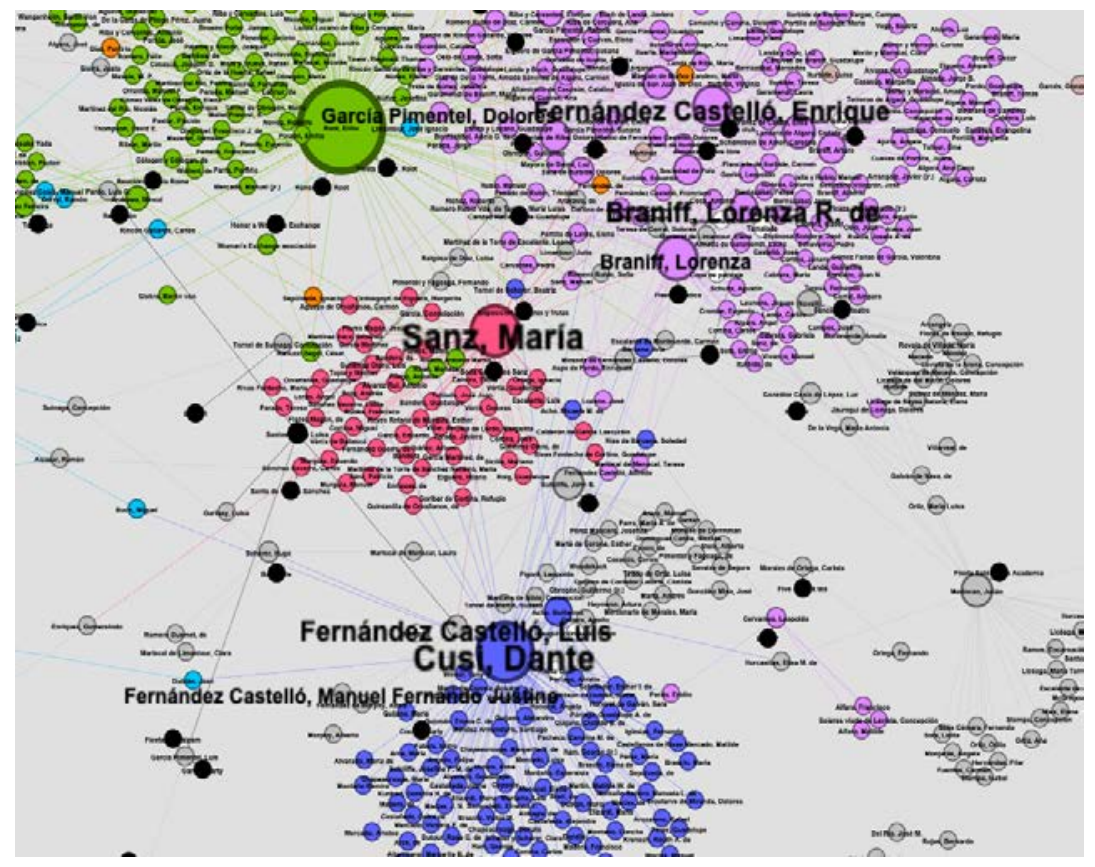

Gráfica 5. Relaciones de Sanz y Cusi. Elaboración propia.

Como se puede apreciar, los nodos más grandes de la red coinciden con apellidos sobresalientes de la clase alta. Pero también hay algunos que, aunque son pequeños en comparación con la red, están relacionados con muchos de los nodos grandes, tienen mayor centralidad de intermediación nodal, y su importancia radica en su papel de intermediarios entre distintos grupos que formaban parte de la misma élite privilegiada, tal es el caso de los García Pimentel y los Fernández Castelló (Gráfica 6). Quizás no fungieron como anfitriones, pero sí como invitados en diferentes círculos sociales. El ingeniero Enrique Fernández Castelló era parte del círculo de amigos de Porfirio Díaz, fue incluso a quien le envió una carta desde el exilio ya en 1911. ${ }^{52}$ Luis García Pimentel era un hacendado propietario de Santa Ana Tenango y Santa Clara Monterfalco en Morelos. ${ }^{53}$

52 Ávila, Castellanos, Hernández, Porfirio Díaz y el Derecho. Balance crítico, pp. 499.

53 Barreto, “La familia García Pimentel y los hacendados frente al reparto agrario”, pp. 13-19. 


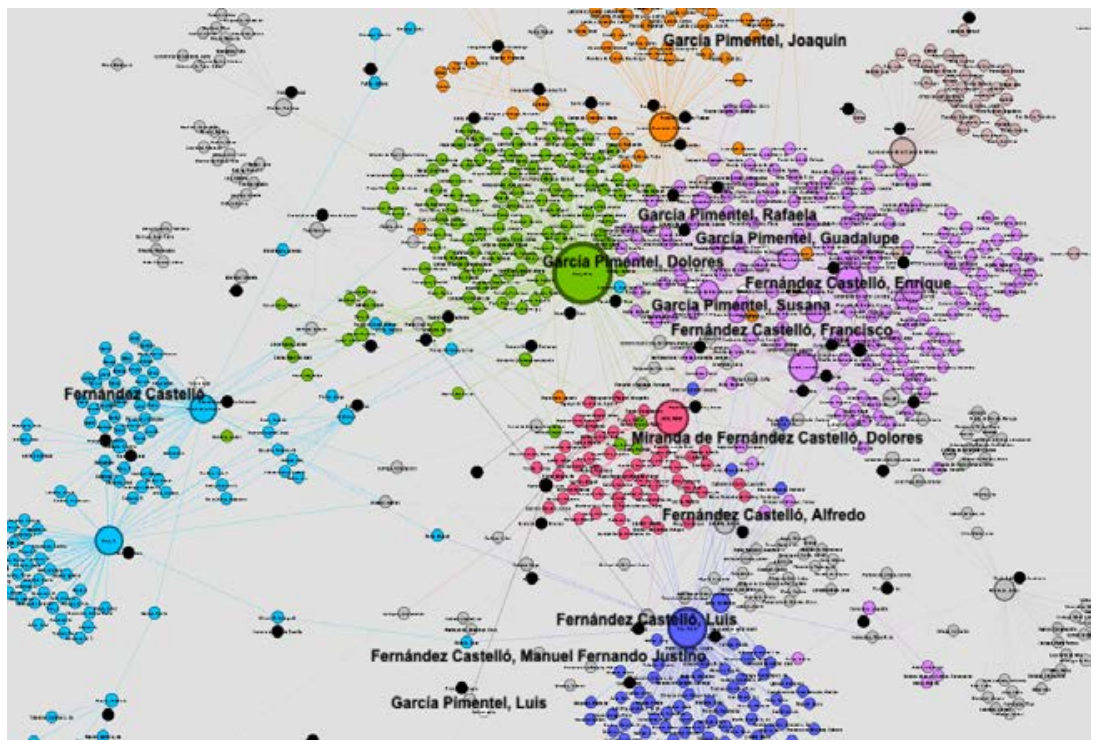

Gráfica 6. Fernández Castelló y García Pimentel. Elaboración propia.

El nodo de Luis García Pimentel aparece poco conectado, sin embargo, fue anfitrión de tres eventos: Garden party, una fiesta en su casa de Tlalpan, y el día de su santo. Lo que sucede es que en la revista no se redactaron los nombres de sus invitados. Por otra parte, los nodos de sus familiares, incluyendo a su esposa Susana Elguero de García Pimentel, están muy relacionados, sobre todo con los eventos Braniff y con la clase política.

Enrique Fernández Castelló sí aparece rodeado de muchos nodos, entre los Braniff y los García Pimentel, aunque Luis y Manuel Fernández Castelló parezcan más apartados. En la redacción de la fiesta de bienvenida a los marinos franceses incluyeron a uno de los Fernández Castelló, pero no pusieron su nombre, por lo que hay un nodo con el apellido solamente entre ese grupo de nodos. No obstante, sin tener el nombre sabemos que la familia Fernández Castelló, los García Pimentel, así como otros apellidos cuyos nodos no sobresalen en este análisis, pero que sí están presentes (Limantour, Riba, Cervantes, Iturbide, Romero Dusmet, etc.), fueron familias importantes en la época del porfiriato, adineradas, propietarias de haciendas, de negocios, de empresas familiares, y que coincidían en los principales eventos sociales. 


\section{REFLEXIONES FINALES}

Siendo los inicios del siglo xx en México, con una visión política de progreso relacionada a la internacionalización europeizante, resulta interesante realizar un acercamiento a las formas en las que los medios impresos intentan configurar -a través de publicaciones dirigidas a la mujer- el modelo de la dama de familia adecuado a los objetivos sociales del país, saber cómo debía ser este modelo, y conocer además a quienes llevaban a cabo esta tarea y sus conexiones con las esferas públicas y políticas; aunque este proceso de configuración del rol femenino es un punto que no se desarrolla a profundidad en este artículo, podría ser un tema para examinar a partir de este acercamiento.

Analizar algunas de las secciones de Álbum de Damas ha sido revelador en cuanto a su intención, similar a la de otras revistas de la época dedicadas a las mujeres, de educar a la mujer mexicana de acuerdo con un modelo que cumpliera con los roles convenientes para la nación y para el desarrollo de los futuros ciudadanos que servirían a la patria. Pero centrar el análisis en la sección social de la revista nos presenta toda una nueva perspectiva, a través del análisis de redes se pueden visibilizar conexiones muy reveladoras en cuanto a vida social, política, estatus, influencias de poder, economía.

El análisis de las redes aristocráticas de cualquier época es un proceso complejo. Se requieren muchos pasos, revisiones a fondo de diferente tipo de documentos, un pensamiento crítico que vea más allá de lo obvio que pueda resultar en una gráfica. Específicamente el período conocido como porfiriato es también un momento complejo de la historia de México, uno muy interesante y que ha dado para analizar desde muy variadas perspectivas.

En este trabajo se intentó echar una mirada a las redes aristocráticas de México del año 1907, a finales del porfiriato y principios del siglo XX. En este caso, la fuente principal fue la sección Ecos sociales de la quincena, de la revista Álbum de Damas, y el foco de atención fueron los eventos sociales en los que estas familias coincidían y convivían, en los que se puede inferir que intercambiaban ideas, opiniones, críticas, pensamientos que podían o no influir en la toma de decisiones económicas y políticas.

Algo que resalta a simple vista en la gráfica de redes es la división entre los eventos extranjeros y los nacionales, y que a su vez, los extranjeros también estén divididos entre los norteamericanos y los europeos, aunque haya ciertos apellidos de mexicanos que se relacionan con aquellos festejos. El prestigio e influencia, tanto de los extranjeros como de las familias mexicanas aristocráticas, quedó representado visualmente en el tamaño de los nodos y en la cercanía de sus conexiones dentro de la red. La admiración hacia lo que viene de fuera, esa aspiración que se nota incluso en la redacción general 
de la revista, se mantiene en parte por esa división, se desea ser y alcanzar eso que no se es, pero que está tan cerca, conviviendo, pero no mezclándose. Ambas partes obtienen ganancias, los extranjeros tienen tratos y privilegios exclusivos, facilidades para hacer negocios que se transforman en capital económico, mientras que los mexicanos adquieren estatus y poder al ser amigos de los admirados.

Entre lo no obvio hay nodos de apellidos que se repiten, que están aquí y allá, entre los extranjeros, los políticos, los comerciantes, en diferentes eventos sociales. Se trata de los nodos que fungen como intermediarios en la red, de personajes que cumplían la función de mantener conexiones entre los miembros de la misma clase alta. Al hacer la búsqueda de información y comparación de datos, se confirma que están ahí por razones importantes, por ser de familias adineradas o cercanas a los círculos políticos. Algunos de ellos son propietarios de haciendas en otros estados, lo que podría explicar por qué sus nodos no son más grandes, pues la revista, aunque se anuncia para distribuirse en los estados, es de producción capitalina, y casi todos los eventos que describe son realizados en la capital.

Respecto a la división de clases de acuerdo con la casta, hay muchos criollos entre la aristocracia, como ejemplo los hijos del matrimonio Braniff o Eduardo Iturbide, de quien no se hizo un análisis más profundo porque en esta revista no tuvo mucha relevancia, pero quien sería gobernador del Distrito Federal durante la dictadura de Victoriano Huerta.

En general, se comprueba que el análisis de la sección social de una revista dirigida a las clases altas puede servir como una ventana a través de la cual podemos asomarnos para observar la vida social de la aristocracia y sus relaciones, y que a través del análisis de redes sociales es posible comprender los procesos de influencia otorgados por una posición privilegiada dentro de la red, mediante las cuales las dinámicas sociales se mezclan con las dinámicas económicas y políticas de esa clase encargada, tal vez de manera indirecta, de dirigir el rumbo del país.

\section{BIBLIOGRAFÍA}

Ávila, Raúl; Castellanos, Eduardo y Hernández, María, Porfirio Díaz y el Derecho. Balance crítico, México, Cámara de Diputados LXIII Legislatura-UNAM, 2015.

Barreto, Carlos, "La familia García Pimentel y los hacendados frente al reparto agrario”, Inventio, vol. 13, núm. 29, 2017, pp. 13-19.

Collado, María, La burguesía mexicana. El emporio Braniff y su participación política 1865-1920, México, Siglo veintiuno, 1987.

Comp. Editorial Arte y Letras, S. A., “A nuestras suscritoras”, Álbum de Damas. Semanario Ilustrado, núm. 54, 1908, p. 7. 
Derreza, Salomón, “Guía de revistas femeninas olvidadas”, Letras libres, 2010, https://www.letraslibres.com/mexico-espana/guia-revistas-femeninasolvidadas, [consultado en mayo de 2019].

Fierro, Rafael, “La casa de don Guillermo de Landa y Escandón”, Grandes casas de México, 2012, https://grandescasasdemexico.blogspot.com/2012/11/la-casade-don-guillermo-de-landa-y.html, [consultado en mayo de 2019].

Fontbona, Francesc, “Las raíces simbolistas del Art Nouveau”, Anales de Literatura Española, núm. 15, 2002, pp. 213-222.

DOI: https://doi.org/10.14198/ALEUA.2002.15.13

Frías, Leticia, "La prensa en tiempos de don Porfirio”, Algarabía, 2017 https://algarabia.com/a-curiosidades/la-prensa-en-tiempos-de-don-porfirio/, [consultado en octubre de 2018].

Garrido, Francisco, “El análisis de redes en el desarrollo local”, Villasante, Tomás; Montañés, Manuel y Martín, Pedro, Prácticas locales de creatividad social. Construyendo ciudadanía 2, Barcelona, Viejo Topo, 2001, pp. 67-89.

“Grandes mejoras en esta revista”, Álbum de Damas. Revista quincenal ilustrada, núm. 9, 1907, p. 1.

Iglesias, Daniel, “El aporte del análisis de las redes sociales a la historia intelectual”, Historia y Espacio, vol. 13, núm. 49, 2017, pp. 17-37.

DOI: https://doi.org/10.25100/hye.v13i49.5880

La Redacción, “A nuestras lectoras”, Álbum de Damas. Revista quincenal ilustrada, núm. 1, 1907, p. 1.

Lozares, Carlos; López-Roldán, Pedro; Bolíbar, Mireia y Muntanyola, Dafne, "La centralidad en las redes sociales: medición, corrección y aplicación”, Metodología de Encuestas, vol. 15, 2013, pp. 77-97.

Luna, María, "Verdad y verosimilitud en la historia: retórica, literatura e historia”, Diálogos. Revista electrónica de historia, vol. 9, 2008, pp. 3773-3807.

DOI: https://doi.org/10.15517/DRE.V9I0.31819.

Martín, Marita, “La Mujer Mexicana (1904 a 1906), una revista de época”, Ethos educativo, núms. 33 y 34, 2005, pp. 68-87.

Molina Enríquez, Andrés, "Las clases sociales mexicanas durante el Porfiriato", Ensayos sobre las clases sociales en México, México, Nuestro Tiempo, 1985, pp. 60-68.

Molina Enríquez, Andrés, Los grandes problemas nacionales, México, Secretaría de Cultura e Instituto Nacional de Estudios Históricos de las Revoluciones de México, 2016.

Molina, José, "El estudio de las redes personales: contribuciones, métodos y perspectivas”, Empiria. Revista de Metodología de Ciencias Sociales, núm. 10, 2005, pp. 71-105. DOI: https://doi.org/10.5944/empiria.10.2005.1044

Ortiz, Julieta, Imágenes del deseo: arte y publicidad en la prensa ilustrada mexicana (1894-1939), vol. 22, México, Universidad Nacional Autónoma de México (UNAM), 2003. 
Pita, Alexandra, "Las revistas culturales como fuente de estudio de redes intelectuales”, Del Palacio, Celia y Martínez, Sarelly, Voces en papel. La prensa en Iberoamérica de 1972 a 1970, Chiapas, Universidad Autónoma de Chiapas, 2008, pp. 77-85.

Pureco, Alfredo, Empresarios lombardos en Michoacán. La familia Cusi entre el porfiriato y la posrevolución (1884-1938), Zamora, El Colegio de Michoacán e Instituto Mora, 2010.

Romero, Gustavo, “Lectura y prácticas ideales. Álbum de damas, 1907-1908”, Correo del maestro, vol. 19, núm. 221, 2014, https://www.correodelmaestro.com/publico/html5102014/capitulo2/album_ de_damas.html.

Saucedo, Carmen, “La victoria de María Conesa”, Relatos e historias en México, vol. XXI, núm. 122, 2018, https://relatosehistorias.mx/nuestras-historias/la-victoria-de-maria-conesa.

Serna, Ana, "Prensa y sociedad en las décadas revolucionarias (1910-1940)", Secuencia, 2014, pp. 111-149.

DOI: https://doi.org/10.18234/secuencia.v0i88.1217.

Tenorio, Mauricio y Gómez, Aurora, El Porfiriato. México, Fondo de Cultura Económica, 2006.

Terán, Aurora, “Instruir a los ángeles del hogar. La educación de las mujeres desde la perspectiva de dos periódicos locales: El Instructor y El Republicano, en la etapa porfiriana”, Investigación y ciencia de la Universidad Autónoma de Aguascalientes, vol. 25, núm. 71, 2017, pp. 77-84.

DOI: https://doi.org/10.33064/iycuaa201771603.

Torres, Morelos y Atilano, Ruth, "La educación de la Mujer Mexicana en la prensa femenina durante el Porfiriato", Revista Historia de la Educación Latinoamericana, vol. 17, núm. 24, 2015, pp. 217-242.

DOI: https://doi.org/10.19053/01227238.3307.

Ugalde, Paola, Arte y Letras o la construcción del imaginario social de la élite porfiriana, 1904-1912, México, Instituto Panamericano de Geografía e Historia, 2013.

Ugalde, Paola, "Instantánea de un porfiriano. Ernesto Chavero: de funcionario público a empresario editorial, 1874-1921”, Revista de Historia de América, núm. 152, 2016, pp. 165-188. DOI: 10.35424/rha.152.2016.359. 